\title{
Correction to: Effect of gamete selection in improving of heat tolerance as demonstrated by shift in allele frequency in maize (Zea mays L.)
}

\author{
Upasana Mohapatra • Ashutosh Singh • R. L. Ravikumar
}

Published online: 29 April 2020

(C) Springer Nature B.V. 2020

\section{Correction to:}

Euphytica (2020) 216:76

https://doi.org/10.1007/s10681-020-02603-z

In the above-mentioned publication, an unfortunate mistake occurred in the title as the scientific name of maize should read: Zea mays L.. The original article has been corrected, and the proper title is also provided here.

Publisher's Note Springer Nature remains neutral with regard to jurisdictional claims in published maps and institutional affiliations.
The original article can be found online at https:// doi.org/10.1007/s10681-020-02603-z.

U. Mohapatra · A. Singh $(\bowtie) \cdot$ R. L. Ravikumar Department of Plant Biotechnology, UAS GKVK Bangalore, Bangalore, Karnataka 560 065, India e-mail: ashutosh@rpcau.ac.in;

singh.ashutosh026@gmail.com

\section{A. Singh}

Centre of Advance Studies on Climate Change, RPCAU,

Samastipur, Bihar 848125, India 